\title{
A Steady State Voltage Stability Analysis of Wind Power Centralized System
}

\author{
Shuo Yang1, Weisheng Wang1, Chun Liu1, Yuehui Huang1, Chi Li', Jing Wang² \\ ${ }^{1}$ China Electric Power Research Institute, Haidian District, Beijing, China \\ ${ }^{2}$ Electric Power Planning and Engineering Institute, Xicheng District, Beijing, China \\ Email: yangshuo@epri.sgcc.com.cn,wangws@epri.sgcc.com.cn, liuchun@epri.sgcc.com.cn, huangyh@epri.sgcc.com.cn, \\ lichi@epri.sgcc.com.cn,jingwang@cpecc.net
}

How to cite this paper: Yang, S., Wang, W.S., Liu, C., Huang, Y.H., Li, C. and Wang, J. (2017) A Steady State Voltage Stability Analysis of Wind Power Centralized System. Energy and Power Engineering, 9, 317-327.

https://doi.org/10.4236/epe.2017.94B037

Received: March 7, 2017

Accepted: March 30, 2017

Published: April 6, 2017

\begin{abstract}
It is significant to research the voltage stability of the wind power centralized system (WPCS) for the effective development of the large scale clustering wind energy resources. A steady state voltage stability analysis of the WPCS by employing the PV curve and model analysis is proposed to reveal the voltage stability influence from different aspects. The PV curve is utilized to trace and indicate the voltage collapse point of the WPCS when the small disturbance of wind power is increased gradually. Then the steady state voltage instability modes of the WPCS are analyzed by calculating the bus participation factors of the minimum eigenvalue model at the collapse point. The simulation results of an actual WPCS in North China show that the static state voltage instability mode of the WPCS is closely related to the operating features and control strategies of different reactive power sources. In addition, the implementation of the doubly-fed induction generator wind turbine generator voltage control is beneficial to improve the WPCS voltage stability.
\end{abstract}

\section{Keywords}

Wind Power Centralized System, Static State Voltage Stability, Doubly Fed Induction Generator, Wind Turbine Generator, Reactive Power, Model Analysis

\section{Introduction}

Wind power becomes the most rapidly growing renewable energy source due to its mature technology and rich resources. China has been developing the wind power vigorously around the country over the past two decades in order to achieve the low-carbon power system [1] [2]. However, limited by the distribu- 
tion of the wind resources, most of the large-scale wind power centralized systems (WPCSs) under construction or planning are located in the north and northwest parts of the country, which are far away from the major load centers in the eastern and coastal areas. The wind power generated from these wind-rich areas has to be centrally collected and integrated into the power grid by longdistance transmission lines. The current situation is that these regions where the WPCS integrated generally possess the weakly connected grid structure and both the small and large disturbance may worsen the voltage security. On the one hand, the small disturbance like the random fluctuations of the wind power output will cause the voltage fluctuations of the point of common coupling (PCC) [3] [4] [5]. On the other hand, the large disturbance like the short-circuit fault will lead to the wind turbine generators (WTGs) cascading trip-off caused by the reactive power incorporation in the WPCS [6] [7] [8]. Therefore, the voltage stability issues caused by the WPCS integration have become the prominent challenges for the large-scale development of the wind power.

In previous works, many scholars have investigated in voltage stability analysis of the wind power integrated system. The contribution of the voltage stability by the support of the WTGs with full power converters is studied in [9] [10]. The research in [11] utilizes large amounts of historical data to reveal that the constant voltage control of the WTG is beneficial for improving the static state voltage stability (SSVS) of wind integrated system. The technical feasibility and economic costs of the usage of WTGs as the reactive power source is studied in [12]. By analyzing the detailed dynamic simulation model of the doubly-fed induction generator (DFIG) WTG, the dynamic response characteristics during the large disturbance are studied in [13].

It can be seen that the above studies mainly focus on the voltage stability analysis and reactive power control strategy for the single WTG or single wind farm integrated system while the systematic research for the WPCS integration is insufficient. With the gradual increasement of the wind power penetration, the integration of large-scale centralized wind power is bound to take something new to the traditional SSVS analysis. On the one hand, the physical structure features of the WPCS integrated grid and the temporal distribution features of the wind power fluctuation have bring many challenges to the voltage stability. On the other hand, with the rapid spread of the variable speed WTGs like DFIG-WTGs and the FACTS devices, the WPCS is generally equipped with varieties of reactive power sources with different time constant. The coordinated control of multi time scales reactive power sources in the WPCS has become another influential factor to the voltage stability.

Focus on the response features and control coordination of different reactive sources, this paper strives to analyze the SSVS problem of the WPCS systematically. This paper is organized as follows. The analytical methods and the simulation results are respectively presented in Section 2 and Section 3. Finally, the conclusions are drawn in Section 4. 


\section{Analytical Methods}

\subsection{PV Curves Analysis for Voltage Stability Evaluation}

PV curve is a voltage stability evaluation approach by revealing the relationship between the active power variation and the bus voltage changes. The calculation approaches of the PV curves include the repeated power flow (RPF) and the continuous power flow (CPF).

RPF computes each operating point of the PV curves by constantly implementing the conventional power flow. One of the obvious advantages of RPF is that, the capacity constraints and the automatic control strategies of different reactive sources with the variations of active power can be treated accurately and simply. But the conventional power flow can hardly converge near the voltage stability limit due to the singularity of the Jacobian matrix. CPF has four basic elements, such as parameterization, predictor, corrector and step-size control, and uses a predictor-corrector continuation method to trace the solution curves. It can overcome the singularity of the Jacobian matrix near the critical point. But the obvious disadvantages of $\mathrm{CPF}$ are the long computing time and the difficult of considering reactive control strategies.

In order to trace and indicate the voltage collapse point of the WPCS when the small disturbance of wind power is increased gradually and the reactive control strategies are implemented automatically, both RPF and CPF are employed to compute the PV curves in this paper. The RPF is called from the base-case point and implemented repeatedly until the conventional power flow is not convergent. Then the CPF is called to trace the collapse point. The schematic diagram is shown in Figure 1.

\subsection{Model Analysis for Voltage Stability Evaluation}

The modal analysis is a voltage stability assessment technique by computing a specified number of the smallest eigenvalues of a reduced Jacobian matrix [14]. The linearized steady state system power voltage equations are given by

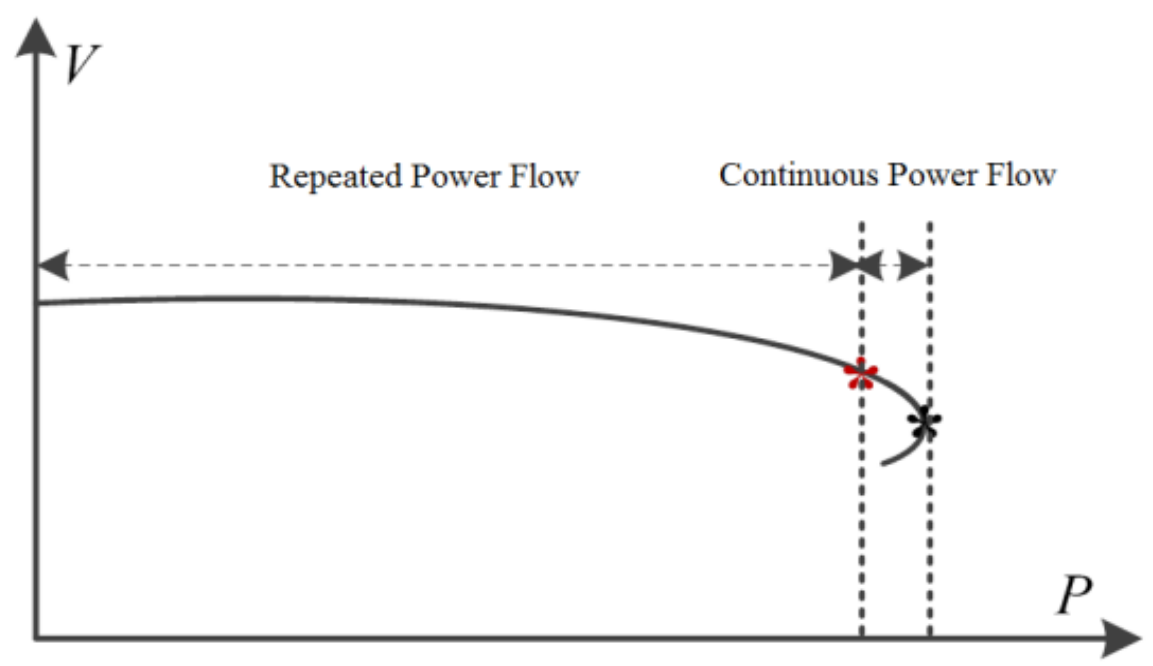

Figure 1. PV curves computing schematic diagram. 


$$
\left[\begin{array}{c}
\Delta P \\
\Delta Q
\end{array}\right]=J\left[\begin{array}{c}
\Delta \theta \\
\Delta V
\end{array}\right]=\left[\begin{array}{ll}
J_{P \theta} & J_{P V} \\
J_{Q \theta} & J_{Q V}
\end{array}\right]\left[\begin{array}{c}
\Delta \theta \\
\Delta V
\end{array}\right]
$$

where $\Delta p$ and $\Delta Q$ are respectively the incremental change in bus active power and reactive power injection, $\Delta \theta$ and $\Delta V$ are respectively the incremental change in bus voltage angle and voltage magnitude, $J$ is the Jacobian matrix.

The voltage stability is affected by both $P$ and $Q$. Here, at each operating point we keep $P$ constant and evaluate voltage stability by considering the incremental relationship between $Q$ and $V$. To reduce Equation (1), let $\Delta p=0$, then

$$
\Delta Q=\left(J_{Q V}-J_{Q \theta} J_{P \theta}^{-1} J_{P V}\right) \Delta V=J_{R} \Delta V
$$

where $J_{\mathrm{R}}$ is called the reduced Jacobian matrix of the system.

According to the Schur decomposition, we have

$$
\|J\|=\left\|J_{P \theta}\right\| \cdot\left\|J_{Q V}-J_{Q \theta} J_{P \theta}^{-1} J_{P V}\right\|=\left\|J_{P \theta}\right\| \cdot\left\|J_{R}\right\|
$$

In view of the fact that $J_{P \theta}$ is always nonsingular, the above equation means that the singularity of the Jacobian matrix is decided by $J_{\mathrm{R}}$.

Transport by eigen-decomposition, Equation (2) can be expressed as

$$
\Delta V=\xi \lambda^{-1} \eta^{T} \Delta Q=\sum_{i} \frac{\xi_{i} \eta_{i}^{T}}{\lambda_{i}} \Delta Q
$$

where $\lambda$ is the diagonal eigenvalue matrix of $J_{\mathrm{R}}, \xi$ and $\eta$ are respectively the right and the left eigenvector matrix of $J_{\mathrm{R}}$. $\xi_{i}$ is the $i$-th column right eigenvector and $\eta_{i}$ the $i$-th row left eigenvector of $J_{\mathrm{R}}$.

It can be seen that, each eigenvalue $\lambda_{\vec{p}}$ and the corresponding right and left eigenvectors $\xi_{i}$ and $\eta_{p}$ define the $i$-th mode of the power system. The magnitude of each eigenvalue $\lambda_{i}$ determines the weakness of the corresponding modal voltage. The smaller the magnitude of $\lambda_{p}$ the weaker the corresponding modal voltage. If $\left|\lambda_{i}\right|=0$, the $i$-th modal voltage will collapse because any change in that modal reactive power will cause infinite modal voltage variation.

The participation factor of bus $k$ to mode $i$ is defined as

$$
P_{k i}=\xi_{k i} \eta_{i k}
$$

From Equation (5), $P_{k i}$ indicates the contribution of $i$-th eigenvalue to the $V$ - $Q$ sensitivity at bus $k$. The bigger the value of $P_{k p}$ the mode $\lambda_{i}$ contributes in determining $V$ - $Q$ sensitivity at bus $k$. For all the small eigenvalues, bus participation factors determine the areas close to voltage instability.

In this paper, the voltage instability modes of the WPCS are analyzed by calculating the bus participation factors of the minimum eigenvalue model at the collapse point.

\section{Case Studies}

\subsection{Description of Simulation System}

An actual WPCS integrated system in North China is utilized to analyze the main influence factors of the SSVS. There are 23 wind farms connected to 4 central substations, and the total installed capability of the WPCS is $2190 \mathrm{MW}$. The 
topology of the simulation system is shown in Figure 2. Considering the simultaneity and correlation of the wind power fluctuation between different wind farms, two typical scenarios are used as the base-case points of the simulation. The scenario 1 represents the balanced and light operating condition, the WPCS wind power is $461.3 \mathrm{MW}$. The scenario 2 represents the unbalanced and heavy operating condition, and the WPCS wind power is $1195.9 \mathrm{MW}$.

Three reactive and voltage control modes are used to compare the influence of different reactive power sources to the WPCS voltage stability:

1) Mode I, the shunt capacitor bank (SCB) and the transformer on load tap changer (OLTC) are the only available reactive power regulation devices in the WPCS. The DFIG-WTGs adopt the unity power factor control method which aims at the reactive power equilibrium of the generators.

2) Mode II, the static var compensator (SVC) and the transformer OLTC are the only available reactive power regulation devices in the WPCS. The control purpose of each SVC is to keep the voltage of the integrated bus as the value at the base-case points. The DFIG-WTGs also adopt the unity power factor control method.

3) Mode III, the DFIG-WTG reactive capacity is taken into account on the basis of Mode I. The DFIG-WTGs adopt the constant voltage control method which aims at keeping the generator terminal bus voltage as the value at the base-case points.
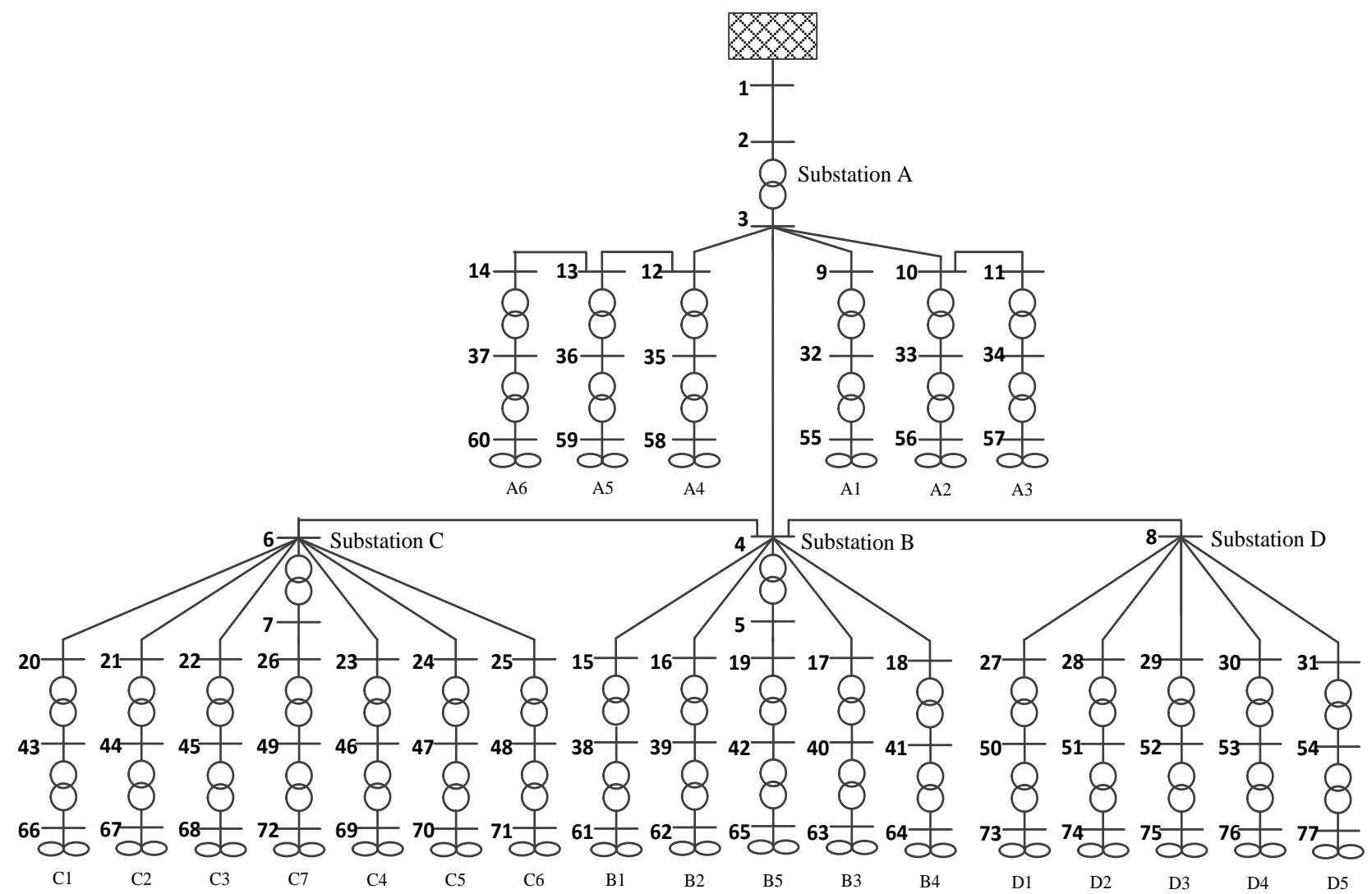

Figure 2. Topology of the simulation system. 


\subsection{PV Curve Analysis Results}

During the calculation of PV curves, the active power output of each wind farm is increased gradually by $0.1 \%$ of its installed capability from the base-case point to the installed capability. The calculation results of the PV curves by using different control modes under the two typical scenarios are respectively shown in Figure 3. The SSVS limit in the PV curve is represented with an asterisk and the statistic result is given in Table 1.

It can be seen from Figure 3 and Table 1 that:

1) In Mode I, the frequent regulations of the SCBs and OLTCs with large step

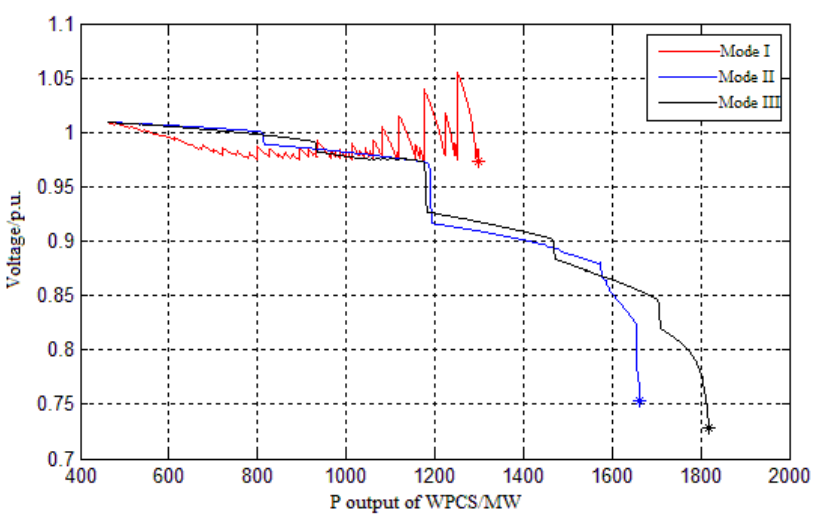

(a)

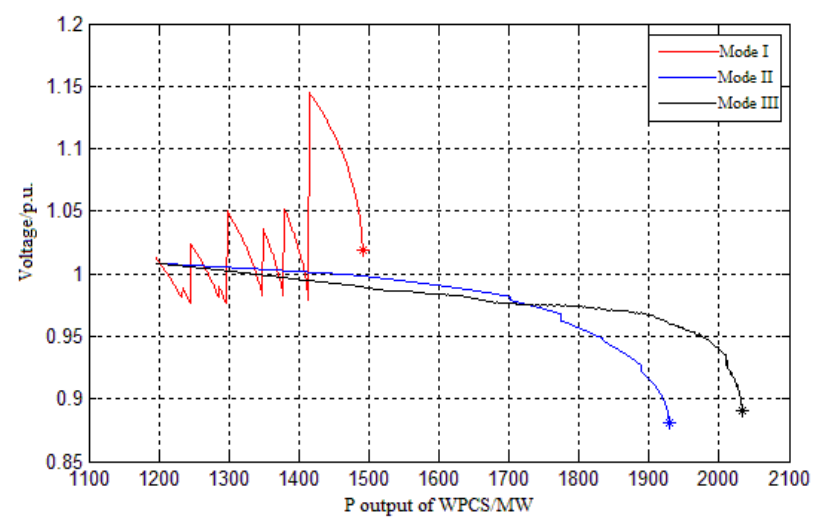

(c)

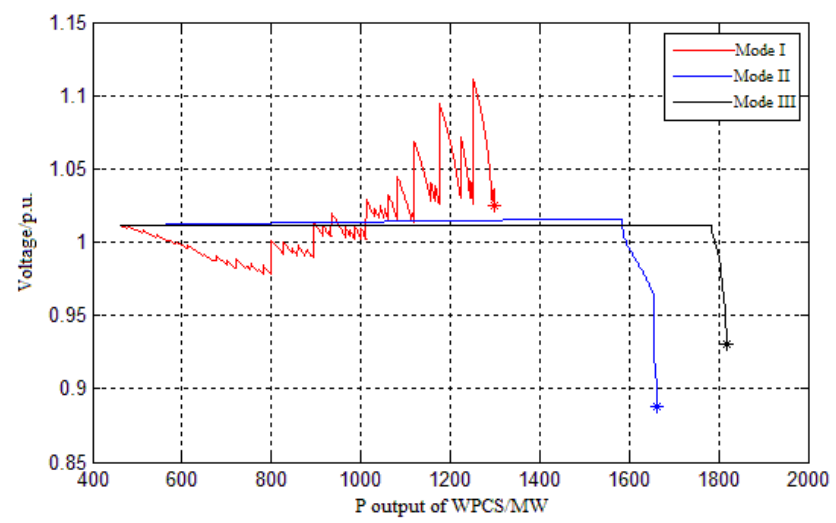

(b)

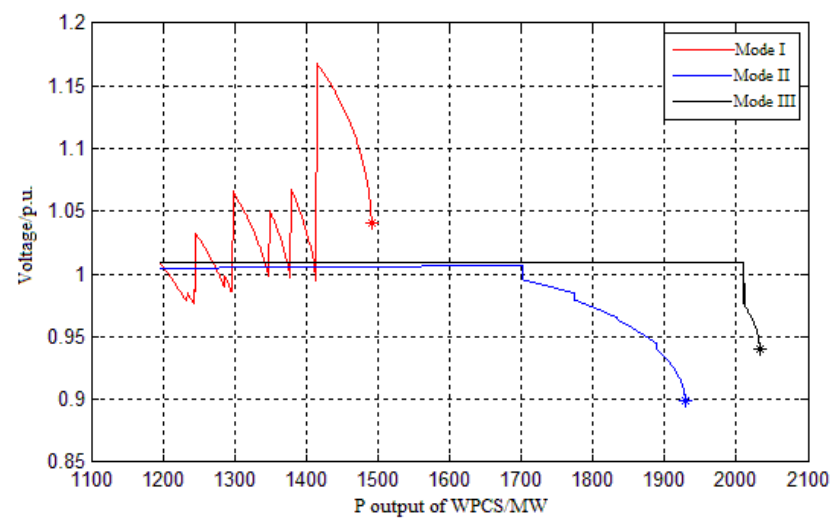

(d)

Figure 3. Some PV curves of different control modes in different Scenarios. (a) PCC bus of B1 in Scenario 1. (b) WTG bus of B1in Scenario 1. (c) PCC bus of D3in Scenario 2. (d) WTG bus of D3in Scenario 2.

Table 1. Statistic results of the SSVS limit/MW.

\begin{tabular}{ccccccc}
\hline \multirow{2}{*}{ WPCS } & \multicolumn{3}{c}{ Scenario 1 } & & \multicolumn{2}{c}{ Scenario 2 } \\
\cline { 2 - 7 } & Mode I & Mode II & Mode III & Mode I & Mode II & Mode III \\
\hline Area A & 348.49 & 446.42 & 485.92 & 391.70 & 516.38 & 539.53 \\
Area B & 307.11 & 393.41 & 430.50 & 333.63 & 425.21 & 446.93 \\
Area C & 443.64 & 568.31 & 621.88 & 464.31 & 645.66 & 699.84 \\
Area D & 199.31 & 255.31 & 279.37 & 301.09 & 341.69 & 346.23 \\
Total & 1298.55 & 1663.45 & 1817.67 & 1490.73 & 1928.94 & 2032.53 \\
\hline
\end{tabular}


size will lead to the fluctuations of the bus voltage in the WPCS. Especially when the operating point is near the voltage stability limit, the regulation of SCBs can easily lead a sharp variation of the generator bus voltage which is disadvantageous for the security operation of the WTGs. For example, in Figure 3(a), the voltage amplitude of the generator terminal bus in B1 wind farm has been more than 1.1 p.u. after the last regulation of the SCBs. This will cause the high voltage trip-off accident of the DFIG-WTGs which don't possess the high voltage ride through capability.

2) In Mode II, the flexible regulation feature of the SVC can keep the bus voltage smooth when the reactive power margin is sufficient. However, once the SVC reaches the upper bound of its reactive power capacity, there will be a sudden drop of the bus voltage which was controlled by the SVC. Compared with Mode I, the static state voltage stability limit values are increased by $28.099 \%$ and $29.395 \%$ for the light and heavy scenarios respectively.

3) Although the reactive power regulation devices, such as the SCBs in Mode I and the SVCs in Mode II, possess the same compensation capability, the SSVS limit of the two control modes are different. Firstly, due to the large regulation step size, every action of the SCBs will markedly change the integrated bus voltage and cause the unbalanced voltage distribution of the whole WPCS. Secondly, during the asynchronous increase of the wind power, the SCBs in the wind farms with high PCC bus voltage value will not further increase the reactive power compensation due to their preset control rules even if the reactive power margin of some other wind farms in the WPCS is insufficient.

4) In Mode 3, by adopting the constant voltage control, the DFIG-WTGs can supply sufficient reactive power which obviously improved the SSVS limit. Before the reactive capacity limit is reached, the DFIG-WTGs can maintain the controlled bus voltage smooth. But when the reactive capacity limit is reached, the bus type of the generator integrated bus is changed from PV to PQ, and then the bus voltage will suddenly drop due to the shortage of the reactive power supply. Compared with Mode I, the SSVS limit values are increased by $39.978 \%$ and $36.344 \%$ for the light and heavy scenarios respectively.

\subsection{Model Analysis}

By implementing the model analysis at the SSVS limit of different operating conditions, the calculated bus participation factors are shown in Figure 4 and Figure 5. The differences between the two figures is that, the participation factors in Figure 4 are ranked by the bus number defined in Figure 2, the participation factors in Figure 5 are ranked by the values in a descending order.

It can be seen from Figure 4 and Figure 5 that:

1) For the different base-case points, the model analysis results of the critical-case points in control mode I always contain a large number of buses with similar participation factors. These results mean that the dU/dQ sensitivity of most WPCS buses at the SSVS limit have the similar value. The size of a bus participation in a given mode indicates the effectiveness of remedial action, applied 


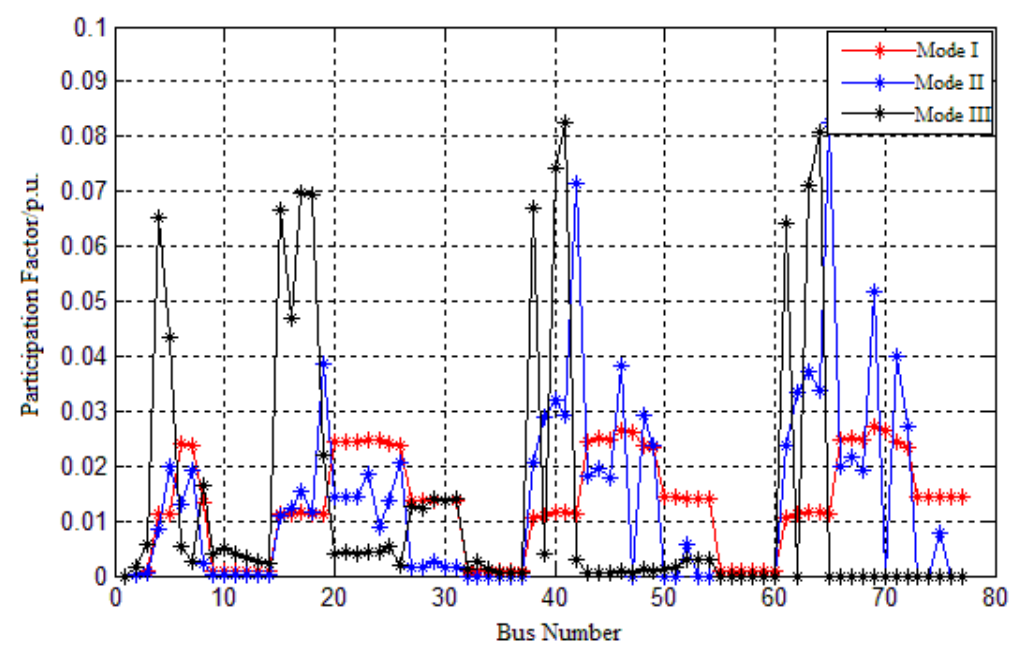

(a)

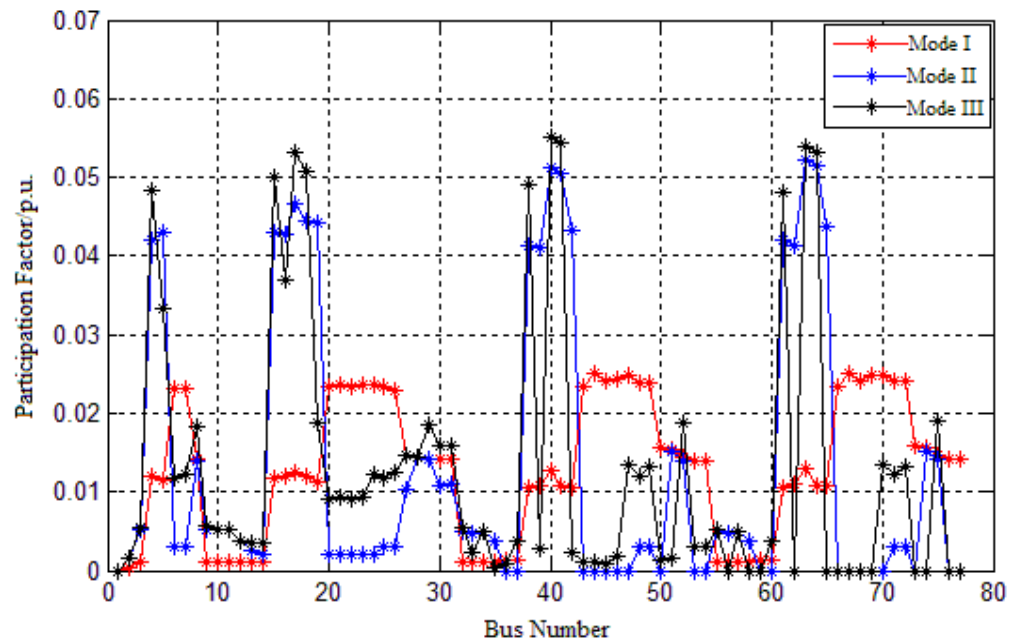

(b)

Figure 4. Bus participation factors ranked by the bus number. (a) Comparisons of Scenario 1. (b) Comparisons of Scenario 2.

at that bus, in a stabilizing the mode. Therefore, under the action of the constant reactive power control method in mode $\mathrm{I}$, the reactive power disturbance or correction control implemented at any of these buses will lead to the approximate effect, and the steady state voltage instability mode of the WPCS is non-localized.

2) Compared with control mode I, the model analysis results of the critical-case points in mode II and mode III always contain a small number of buses with dominant participations and may occur due to WTGs connected buses at the end of long radial transmission lines. This means the steady state voltage instability mode of the WPCS is localized. The reason for this phenomenon is that, by employing the constant voltage control method, the reactive capacity of SVCs and WTGs can be fully utilized, and most of the wind farms' reactive power demand caused by active power variation can be satisfied. A small number of the wind farms which are lacking in reactive power support become the short boards 


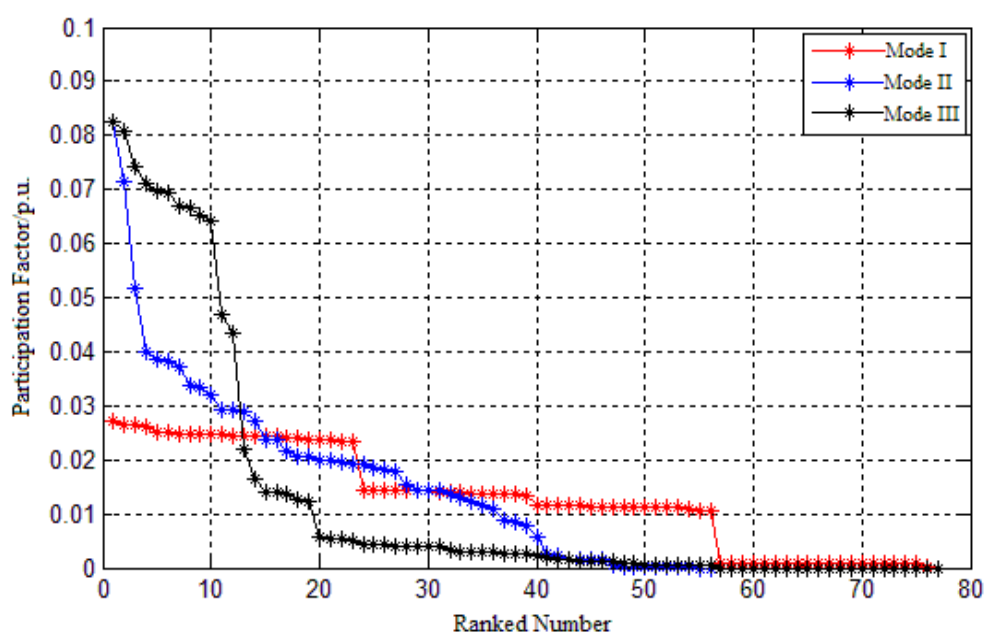

(a)

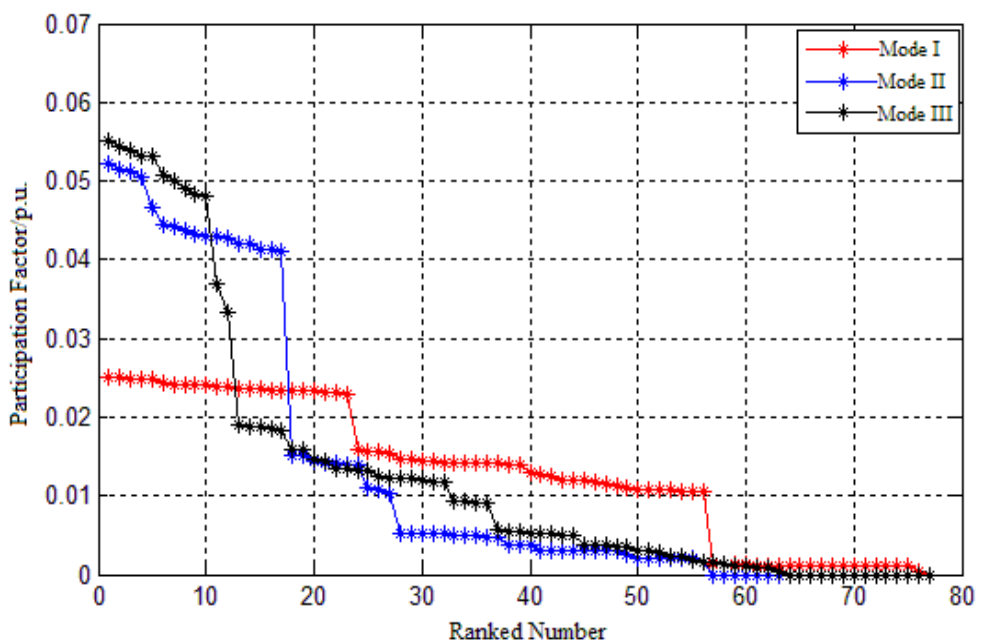

(b)

Figure 5. Bus participation factors ranked by the values in a descending order. (a) Comparisons of Scenario 1. (b) Comparisons of Scenario 2.

of the SSVS when the wind power is constantly increasing.

\section{Conclusion}

In this paper, on the basis of the reactive capacity analysis of the DFIG-WTG, the steady state voltage stability of the WPCS is studied by employing both the PV curve method and model analysis method. The main conclusions cover the followings:

1) The constant reactive power control of the SCBs and the constant unique power factor control of the DFIG-WTG can't maintain the voltage level of the whole WPCS when the wind power is increasing. Especially when the operating point is near the voltage stability limit, the regulation of SCBs can easily lead a sharp variation of the generator terminal bus voltage which is disadvantageous for the security operation of the WTGs. The constant voltage control of the SVCs and DFIG-WTGs can keep the bus voltage smooth and extend the SSVS 
limit.

2) The static state voltage instability mode of the WPCS is closely related to the operating features and control strategies of different reactive power sources. The constant reactive power control of the SCBs always leads to the localized mode, and the constant voltage control of the SVCs and DFIG-WTGs leads to the non-localized mode.

\section{Acknowledgements}

This work has been supported financially by the Science and Technology Project of SGCC.

\section{References}

[1] Chen, Q.X., Kang, C.Q, Ming, H., et al. (2014) Assessing the Low-Carbon Effects of Inter-Regional Energy Delivery in China's Electricity Sector. Renewable and Sustainable Energy Reviews, 32, 671-683. https://doi.org/10.1016/j.rser.2013.12.050

[2] (2014) Global Wind Report Annual Market Update 2014. Global Wind Energy Council.

http://www.gwec.net/wp-content/uploads/2015/03/GWEC_Global_Wind_2014_Rep ort_LR.pdf

[3] Vittal, E., O’Malley, M. and Keane, A. (2010) A Steady-State Voltage Stability Analysis of Power Systems with High Penetrations of Wind. IEEE Transactions on Power Systems, 25, 433-442.https://doi.org/10.1109/TPWRS.2009.2031491

[4] Hossain, M.J., Hemanshu, R.P., Mahmud, M.A., et al. (2012) Investigation of the Impacts of Large-Scale Wind Power Penetration on the Angle and Voltage Stability of Power Systems. IEEE Systems Journal, 6, 76-84.

[5] Rohig, K., Lange, B., Gesino, A., et al. (2009) Wind Power Plant Capabilities: Operate Wind Farms Like Conventional Power Plants. Proceedings of 2009 European Wind Energy Conference, Marseille. https://doi.org/10.1109/JSYST.2011.2162991

[6] Zheng, C. and Kezunovic, M. (2012) Impact of Wind Generation Uncertainty on Power System Small Disturbance Voltage Stability: A PCM-based Approach. Electric Power Systems Research, 84, 10-19.https://doi.org/10.1016/j.epsr.2011.10.001

[7] Gesino, A., Lange, B. and Rohig, K. (2010) Large Scale Integration of Offshore Wind Power through Wind Farm Clusters. Proceedings of Renewable Energy World Europe Conference, Amsterdam.

[8] Vittal, E., Keane, A. and O'Malley, M. (2008) Varying Penetration Ratios of Wind Turbine Technology for Voltage and Frequency Stability. Proceeding of IEEE PES General Meeting, Pittsburgh. https://doi.org/10.1109/pes.2008.4596402

[9] Ullah. N.R. and Thiringer, T. (2006) Effect of Operational Modes of a Wind Farm on the Transient Stability of Nearby Generators and on Power Oscillations: A Nordic Grid Study. NORDIC Wind Power Conference, Finland.

[10] De Rijcke, S., Ergun, H., et al. (2012) Grid Impact of Voltage Control and Reactive Power Support by Wind Turbines Equipped with Direct-Drive Synchronous Machines. IEEE Transactions on Sustainable Energy, 3, 890-898. https://doi.org/10.1109/TSTE.2012.2205167

[11] Vittal, E., O’Malley, M. and Keane, A. (2010) A Steady-State Voltage Stability Analysis of Power Systems with High Penetrations of Wind. IEEE Transactions on Power Systems, 25, 433-442.https://doi.org/10.1109/TPWRS.2009.2031491

[12] Ullah, N.R., Bhattacharya, K. and Thiringer, T. (2009) Wind Farms as Reactive Power 
Ancillary Service Providers-Technical and Economic Issues. IEEE Transactions on Energy Conversion, 24, 661-672. https://doi.org/10.1109/TEC.2008.2008957

[13] Luis, M.F., Francisco, J. and Saenz, J.R. (2006) Dynamic Models of Wind Farms with Fixed Speed Wind Turbines. Renewable Energy, 31, 1203-1230. https://doi.org/10.1016/j.renene.2005.06.011

[14] Habib, S. and Kordi, B. (2013) Calculation of Multi-Conductor Underground Cables High-Frequency Per-Unit-Length Parameters Using Electromagnetic Modal Analysis. IEEE Transactions on Power Delivery, 28, 276-284.

https://doi.org/10.1109/TPWRD.2012.2224382

Submit or recommend next manuscript to SCIRP and we will provide best service for you:

Accepting pre-submission inquiries through Email, Facebook, LinkedIn, Twitter, etc. A wide selection of journals (inclusive of 9 subjects, more than 200 journals) Providing 24-hour high-quality service User-friendly online submission system Fair and swift peer-review system Efficient typesetting and proofreading procedure Display of the result of downloads and visits, as well as the number of cited articles Maximum dissemination of your research work

Submit your manuscript at: http://papersubmission.scirp.org/

Or contact epe@scirp.org 